\title{
BMJ Open Effect of emotional content on online video sharing among health care professionals and researchers (DIFFUSION): results and lessons learnt from a randomised controlled trial
}

\author{
Junko Kiriya, ${ }^{1}$ Phil Edwards, ${ }^{2}$ Ian Roberts ${ }^{3}$
}

To cite: Kiriya J, Edwards P, Roberts I. Effect of emotional content on online video sharing among health care professionals and researchers (DIFFUSION): results and lessons learnt from a randomised controlled trial. BMJ Open 2018;8:e019419. doi:10.1136/ bmjopen-2017-019419

- Prepublication history and additional material for this paper are available online. To view these files, please visit the journal online (http://dx.doi. org/10.1136/bmjopen-2017019419).

Received 1 September 2017 Revised 20 December 2017 Accepted 24 January 2018

Check for updates

${ }^{1}$ Community and Global Health, Graduate School of Medicine, the University of Tokyo, Tokyo, Japan

${ }^{2}$ Department of Population Health, London School of Hygiene and Tropical Medicine, London, UK

${ }^{3}$ Department of Population Health, London School of Hygiene and Tropical Medicine, London, UK

Correspondence to

Dr Junko Kiriya;

junk00511@gmail.com

\section{ABSTRACT}

Objectives We assessed the effect of emotional content on the extent to which online videos are shared among health professionals.

Setting We conducted a two-arm randomised controlled trial. We sent a link to one of two videos by email to participants asking them to watch the video and forward it to their colleagues.

Participants Health professionals and researchers (obstetrics, gynaecology and midwifery) with an email address apart from those in countries where access to YouTube is banned. We estimated that 7000 participants were required.

Interventions We compared two online videos providing background information about the WOMAN trial. The videos were the same length and had the same content. However, the intervention video had more emotional impact than the control video.

Outcome measures The primary outcome was video sharing and the secondary outcome was views generated by participants. We conducted a $\chi^{2}$ test for the primary outcome and t-test for the secondary outcome.

Results We randomly allocated 8353 email addresses, 4178 to the intervention video and 4175 to the control. Of these, 221 (5.3\%) watched the intervention video and $215(5.1 \%)$ watched the control. In the intervention group, $44(1.1 \%)$ forwarded the video compared with $37(0.9 \%)$ in the control group (risk ratio 1.2 [95\% $\mathrm{Cl} 0.8$ to 1.8$]$, $p=0.44)$. Mean number of views generated by participants allocated to the intervention video was 0.04 and the control video was 0.03 (mean difference $0.01[95 \% \mathrm{Cl}$ -0.02 to 0.04$], p=0.53$ ).

Conclusions We found no evidence that emotional content increased forwarding. The trial had low power due to the low video watching rate and the small number of outcome events. A key challenge for online dissemination is ensuring recipients watch the video.

Trial registration number NCT02109159; Results.

\section{INTRODUCTION}

Research results with important implications for public health must be disseminated widely. However, current dissemination strategies
Strengths and limitations of this study

- Ours is the first trial to examine the effect of emotional content on video sharing among health professionals.

- As there was no way to detect email forwarding or video sharing precisely, there was a chance of misclassification in the outcome assessment and sharing might have been overestimated or underestimated.

- We took other possible scenarios for detecting video sharing into account in sensitivity analyses using different types of data.

- We learnt from this trial that when disseminating an online video by email, only a small group of people watch the video. Hence, dissemination via email might be inefficient unless a better way is developed to improve video viewing rate.

such as continuing medical education and the distribution of guidelines do not achieve rapid global dissemination. The internet provides opportunities for rapid dissemination at low cost, especially if recipients share information online. Brief online videos could help doctors to keep up to date and draw their attention to new evidence. Research on the potential of online videos as a dissemination tool is emerging. ${ }^{12}$ Because person-to-person sharing accounts for nearly half of the view counts of newly uploaded videos, ${ }^{3}$ understanding why people share online content is important.

A strong emotional narrative is believed to promote information sharing. ${ }^{4-7}$ A randomised trial of the effect of emotional content on online sharing by university students found that strong emotions, such as happiness or anger, increased sharing. ${ }^{8}$ However, our systematic search failed to identify any trials in health professionals. We conducted a randomised controlled trial of the 
effect of emotional content on video sharing among health professionals and researchers.

\section{METHODS}

\section{Study design}

The DIFFUSION (Disseminating Findings Fast Using Online videos) trial is a two-arm randomised controlled trial. We compared two online videos providing background information about the WOMAN trial, a large international trial of tranexamic acid in postpartum haemorrhage. The videos were the same length (approximately $2.5 \mathrm{~min}$ ) and had the same content. However, the intervention video had more emotional impact (an interview with a postpartum haemorrhage survivor and her husband) than the control video (the interviewer describes their experience). A difference in the emotion impact of the videos had been established in a cross-over trial prior to the DIFFUSION trial (see online supplementary file 1 ). The videos were uploaded on a closed YouTube channel and the trial was conducted online. We sent participants an email message with a link to the allocated video. We invited them to watch the video and to forward it to their colleagues if they found it helpful. We prepared a computer programme to monitor access to the videos. We had previously conducted a pilot trial to test the eligibility of the trial procedure for the main DIFFUSION trial. Based on the lessons learnt from this pilot trial, we estimated the sample size and prepared the invitation email.

This study was approved by the ethics committee of the London School of Hygiene and Tropical Medicine (reference no. 8850). The study is registered as ClinicalTrials.gov NCT02109159 and the protocol was submitted prior to the start of this study (now it is 'Completed' and results are available on the website of ClinicalTrials.gov).

\section{Sample size estimate}

We estimated that $10 \%$ of emails would be forwarded. ${ }^{9-13}$ In the pilot trial, we found that only $14 \%$ of those to whom we sent the email watched the videos. On the basis of these proportions, we estimated that a study of 7000 participants would have $90 \%$ power to detect a $7.5 \%$ difference in forwarding at the $5 \%$ level of significance.

\section{Participants}

Health professionals and researchers (obstetrics, gynaecology and midwifery) with an email address apart from those in countries where access to YouTube is banned (China, ${ }^{14}$ Iran, ${ }^{15}$ Pakistan, ${ }^{16}$ Turkmenistan ${ }^{17}$ ) were included. Three trial assistants screened obstetrics and gynaecology and midwifery journals published between 2013 and August 2014 for author email addresses. We also included health professionals who had expressed an interest in joining the WOMAN trial.

\section{Randomisation and masking}

Eligible email addresses were assigned sequential identification numbers (ID numbers). An independent statistician, who was masked to the email addresses, allocated the ID numbers to the intervention or control group using a computer-generated allocation sequence (1:1

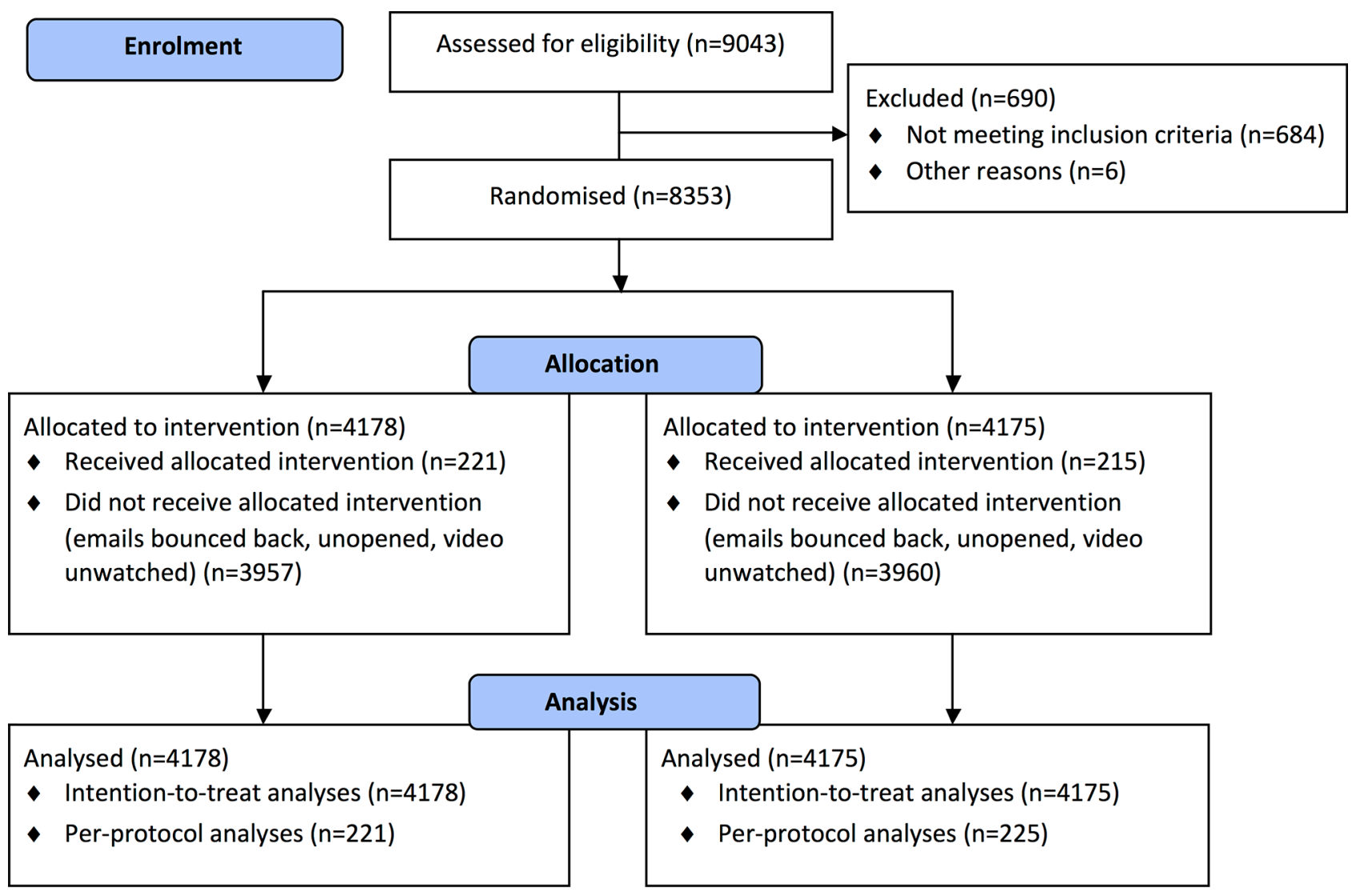

Figure 1 Flow diagram of participants. 
Table 1a Characteristics of all participants randomised Intervention video

Control video

\begin{tabular}{lll}
\hline $\begin{array}{l}\text { All participants } \\
\text { randomised } \\
\text { Country }\end{array}$ & 4178 & 4175 \\
\hline $\begin{array}{l}\text { Low-income } \\
\text { countries } \\
\text { Lower-middle- } \\
\text { income countries } \\
\begin{array}{l}\text { Upper-middle- } \\
\text { income countries }\end{array}\end{array}$ & $964(11.1 \%)$ & $457(11.0 \%)$ \\
\hline $\begin{array}{c}\text { High-income } \\
\text { countries }\end{array}$ & $507(12.1 \%)$ & $543(13.0 \%)$ \\
\hline $\begin{array}{c}\text { Source of contact } \\
\text { WOMAN trial }\end{array}$ & $2273(54.4 \%)$ & $2331(55.8 \%)$ \\
\hline $\begin{array}{c}\text { contact list } \\
\text { Journals }\end{array}$ & $1308(31.3 \%)$ & $1263(30.3 \%)$ \\
\hline
\end{tabular}

Table 1b Characteristics of those who watched the videos

\begin{tabular}{|c|c|c|}
\hline & $\begin{array}{l}\text { Intervention } \\
\text { video }\end{array}$ & Control video \\
\hline $\begin{array}{l}\text { Participants who } \\
\text { watched the video }\end{array}$ & $221 / 4178$ (5.3\%) & $215 / 4175$ (5.2\%) \\
\hline \multicolumn{3}{|l|}{ Country } \\
\hline $\begin{array}{l}\text { Low-income } \\
\text { countries }\end{array}$ & 41 (18.6\%) & $29(13.5 \%)$ \\
\hline $\begin{array}{l}\text { Lower-middle- } \\
\text { income countries }\end{array}$ & 67 (30.3\%) & $58(27.0 \%)$ \\
\hline $\begin{array}{l}\text { Upper-middle- } \\
\text { income countries }\end{array}$ & $26(11.8 \%)$ & $34(15.8 \%)$ \\
\hline $\begin{array}{l}\text { High-income } \\
\text { countries }\end{array}$ & 87 (39.4\%) & $94(43.7 \%)$ \\
\hline \multicolumn{3}{|l|}{ Source of contact } \\
\hline $\begin{array}{l}\text { WOMAN trial } \\
\text { contact list }\end{array}$ & $102(46.2 \%)$ & $89(41.4 \%)$ \\
\hline Journals & 119 (53.9\%) & 126 (58.6\%) \\
\hline
\end{tabular}

randomisation). Outcome assessment and data analysis was also masked to the names and email addresses of participants as well as intervention allocation.

\section{Invitation email}

In the pilot trial, we used Google mail merge service to send personalised mass email messages to trial participants from Gmail accounts created for the study under the name of a Professor at the London School of Hygiene and Tropical Medicine (LSHTM). In the main phase, we sent emails from an email account of LSHTM under the name of the coordinator of this trial (JK) using a mass email service, Campaign Monitor. We assumed it was more likely that participants would open an email from a university account than from a Gmail account. We also altered the subject line and the main text of the email message to make them more attractive and encourage the recipients to open the message and click on the link to the videos (see online supplementary file 2). Wainer and colleagues found curiosity is a key to attract recipients to open the email. ${ }^{18}$ On the other hand, busy recipients may prefer subject lines that indicate the content of the message. Therefore, we composed a subject line that suggested the content of the email and that might make the recipients curious.

\section{Outcomes}

The primary outcome was video sharing. The secondary outcome was views generated from video sharing by each participant. Each participant received a unique link to the allocated video with an ID number, by which we recognised their access to the videos. Using the data collected by the computer programme, we judged that the video was shared by participants if there was multiple access to the video from the same ID number by more than one IP address (defined as different device in this study). As for the secondary outcome, we counted the number of views from different devices with the same ID number.

The number of views that mainly resulted from video sharing declines towards zero within 14 days of upload. ${ }^{3}$ Therefore, we used the data collected until 15th day of sending the email for the analyses.

\section{Statistical analysis}

We used a standard $\chi^{2}$ test as the primary test of statistical significance of the effect of the intervention on video sharing and calculated risk ratio with $95 \%$ CIs. We conducted a t-test and a Mood's median test ${ }^{19}$ to test the statistical difference in the mean and median of the number of views generated as a result of video sharing by each participant, respectively. We conducted all analyses on both intention-to-treat (ITT: allocated video) and per-protocol (PP: viewed video) bases.

\section{RESULTS}

We randomised 8353 email addresses, 4178 to the intervention and 4175 to the control video. Emails were sent

Table 2 Number of sharing

\begin{tabular}{lllll} 
& & & Risk ratio & \\
& Intervention video & Control video & (95\% Cl) & P value \\
\hline Shared/allocated (ITT) & $44 / 4178(1.1 \%)$ & $37 / 4175(0.9 \%)$ & $1.2(0.8$ to 1.4) & 0.44 \\
Shared/watched (PP) & $44 / 221(19.9 \%)$ & $37 / 215(17.2 \%)$ & $1.2(0.8$ to 1.7$)$ & 0.47 \\
\hline
\end{tabular}


Table 3 Mean number of views generated

Intervention video

(95\% Cl)

Control video $(95 \% \mathrm{Cl}) \quad$ Difference $(95 \% \mathrm{Cl}) \quad$ P value

\begin{tabular}{lllll}
\hline Mean of views (ITT) & $0.04(0.01$ to 0.07$)$ & $0.03(0.01$ to 0.05$)$ & $0.01(-0.02$ to 0.04$)$ & 0.53 \\
Mean of views (PP) & $0.7(0.2$ to 1.2$)$ & $0.5(0.2$ to 0.9$)$ & $0.2(-0.5$ to 0.8$)$ & 0.56 \\
\hline
\end{tabular}

on 20 November 2014 and data were collected until 4 December 2014. A total of $221(5.3 \%)$ intervention participants watched the video and $215(5.2 \%)$ control participants. The video viewing rate was much lower than that of the pilot trial $(14.0 \%)$. Figure 1 shows the trial profile. The baseline characteristics were balanced between intervention and control participants (table 1). As only names, email addresses and affiliations of participants were available from the journals, we cannot examine sociodemographic characteristics of participants.

In the intervention group, $1.1 \%(44 / 4178)$ of those who were randomised shared the video, and $0.9 \%$ $(37 / 4175)$ of those who were randomised shared the control video (risk ratio 1.2 [95\% CI 0.8 to 1.8 ], $\mathrm{p}=0.44$ ). In the intervention group, $19.9 \%(44 / 221)$ of those who watched the video shared it, and $17.2 \%(37 / 215)$ of those who watched the control video shared it (1.2 [0.8 to 1.7], $\mathrm{p}=0.47$ ). Table 2 summarises the results.

The average number of views generated as a result of video sharing by the participants in the intervention group was 0.04 (95\% CI 0.01 to 0.07$)$ and by those in the control group was 0.03 (0.01 to 0.05$)$. The difference between the two groups was $0.01(-0.02$ to $0.04, \mathrm{p}=0.53)$.
The average number of views generated by the participants who watched the intervention video was 0.7 (0.2 to 1.2) and by those who watched the control video was 0.5 (0.2 to 0.9$)$. The difference between the two groups was $0.2(-0.5$ to $0.8, \mathrm{p}=0.56)$. The median number of views was zero in both groups. Table 3 summarises the results.

Figure 2 presents the distribution of the number of views generated by participants. Most participants did not share the video. The histograms do not include those who did not share the videos.

\section{DISCUSSION}

There was no significant difference in forwarding between the videos. Because only $5 \%$ of participants watched the videos, the number of outcome events (forwarding) was low and the trial had low power. However, absence of evidence is not evidence of absence and further studies are needed to confirm or refute an effect on sharing.

Before conducting the trial, the email message was only considered as a tool to deliver the videos. However, it turned out to be an important aspect. One possible reason for the low viewing rate is that some of the

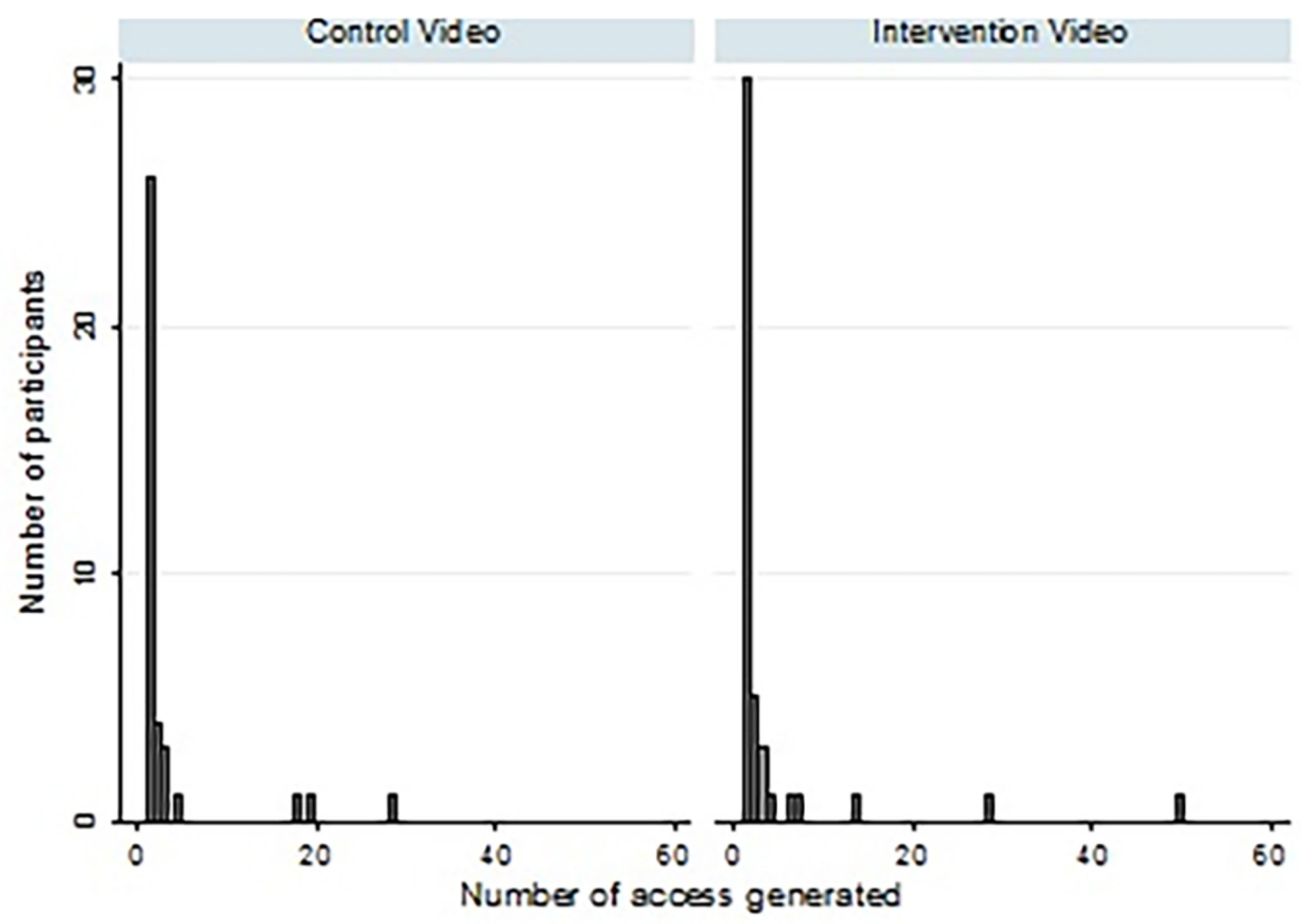

Figure 2 Distribution of the number of views each participant generated. 
participants in the main trial participated in the pilot trial. We included those who had not opened the email in the pilot study and these recipients might have been least likely to open an unsolicited email. Another reason could be the name of the sender changed from a professor in the pilot trial to a trial coordinator in the main study. In retrospect, more attention should have been paid during the process of developing the invitation email to the name under which the emails were sent, which email addresses were used, and the subject line and main text of the email.

Ours is the first trial to examine the effect of emotional content on video sharing among health professionals. Participants were randomised and allocation was well concealed. As there was no way to detect email forwarding or video sharing precisely, we defined 'access from a different IP address (device)' as 'access from different person' for the outcome assessment. However, this raised the risk of misclassification in the outcome assessment as the same person could access the video from different devices (e.g., computer and smartphone). Another issue is that we cannot always identify different devices from IP addresses because some organisations have only group IP address open to public but not individual IP address. There were different possible scenarios, but we could not confirm which case each access was. Therefore, sharing might have been overestimated or underestimated. We took other possible scenarios into account in sensitivity analyses using data of the type of device and time of access collected by the computer programme (see online supplementary file $3)$.

We learnt from this trial that when disseminating an online video by email, only a small group of people watch the video. Hence, dissemination via email might be inefficient unless a better way is developed to improve video viewing rate.

To obtain a more precise estimate of the effect of an emotional online video on sharing, another randomised controlled trial with a sufficient number of people who watch the videos is required. As we learnt from this trial, increasing video viewing rate is difficult. To improve the video viewing rate when conducting another trial using emails, we need to explore factors in email subject lines and main texts that encourage recipients to open it and click the link. A study to examine the factors associated with email opening and link clicking is needed.

Acknowledgements We are grateful to Dr David Prieto for his advice on the statistical analyses. We also appreciate Mr Hakim Miah's contribution to this study by creating a computer programme for data collection.

Contributors JK planned and conducted the trial. She also analysed the data and wrote the manuscript of this article. PE supervised statistical analyses of this study and conducted randomisation of participants. IR contributed to conception and design of this trial and is responsible to give final approval of the manuscript.

Funding This research received no specific grant from any funding agency in the public, commercial or not-for-profit sectors.

Competing interests None declared.
Patient consent Not required.

Ethics approval This study received ethical committee approval from the London School of Hygiene and Tropical Medicine (reference no. 8850). This study is registered as ClinicalTrials.gov NCT02109159. Participants are not patients, they are not vulnerable and which of the two links they receive will have no adverse impact on any aspect of their health or well-being. They can exercise their autonomy by deleting the message, watching the video, not watching the video or whatever they want. Therefore, we concluded that it was ethical not to tell individuals that we will assess the extent to which the two different videos and watched and forwarded using publicly available anonymous data and there was no need to obtain consent to participate.

Provenance and peer review Not commissioned; externally peer reviewed.

Data sharing statement The datasets generated and analysed during the current study are available from the corresponding author on reasonable request.

Open Access This is an Open Access article distributed in accordance with the Creative Commons Attribution Non Commercial (CC BY-NC 4.0) license, which permits others to distribute, remix, adapt, build upon this work non-commercially, and license their derivative works on different terms, provided the original work is properly cited and the use is non-commercial. See: http://creativecommons.org/ licenses/by-nc/4.0/

(c) Article author(s) (or their employer(s) unless otherwise stated in the text of the article) 2018. All rights reserved. No commercial use is permitted unless otherwise expressly granted.

\section{REFERENCES}

1. DeWitt D, Alias N, Siraj S, et al. The potential of Youtube for teaching and learning in the performing arts. Procedia Soc Behav Sci 2013;103:1118-26.

2. Godwin HT, Khan M, Yellowlees P. The educational potential of YouTube. Acad Psychiatry 2017;41:823-7.

3. Broxton T, Interian $\mathrm{Y}$, Vaver J, et al. Catching a viral video. J Intell Inf Syst 2013;40:241-59.

4. Godin S. Unleashing the ideavirus. New York: Do You Zoom, Inc, 2001. http://www.sethgodin.com/ideavirus/downloads/ideavi rusreadandshare.pdf (cited $7 \mathrm{Jul}$ 2015).

5. Dobele A, Lindgreen A, Beverland M, et al. Why pass on viral messages? Because they connect emotionally. Bus Horiz 2007;50:291-304.

6. Nelson-Field K, Riebe E, Newstead K. The emotions that drive viral video. Australas Mark J 2013;21:205-11.

7. Guadagno RE, Rempala DM, Murphy S, et al. What makes a video go viral? An analysis of emotional contagion and Internet memes. Comput Human Behav 2013;29:2312-9.

8. Berger J, Milkman KL. What makes online content viral? J Mark Res 2012;49:192-205.

9. Bureau VDT convention \& visitors. Email marketing 101: tips \& tricks to become an email marketing rockstar. $2011 \mathrm{http}: / / w w w . d e n v e r . o r g /$ pdfs/EmailTips.pdf

10. Finkelstein J. Email marketing case study: video email campaign. 2004. http://www.customerparadigm.com/email-marketing-casestudy-video-email-campaign/

11. International DMA. Measuring DMO digital marketing efforts: it's more than just clicks. 2010. http://www.slideshare.net/mpsarros/dm o-digital-mediameasurementssomar

12. Izawa M. What makes viral videos viral?: Roles of emotion, impression, utility, and social ties in online sharing behavior. Baltimore, Maryland: Johns Hopkins University, 2010. http:// advanced.jhu.edu/wp-content/uploads/2013/04/Izawa-Thesis-Final. pdf

13. Look G. Tracking - what can it tell you? 2011. http://www.greatlook. com.au/article6.html

14. BBC NEWS TECHNOLOGY. China blocks access to Bloomberg and Businessweek site. 2012. http://www.bbc.co.uk/news/technology18648050 (cited 24 Sep 2013).

15. CNN. Iran blocks YouTube, Google over Mohammed video. Staff CNNW, editor. 2012. http://edition.cnn.com/2012/09/24/world/ meast/iran-youtube-blocked/index.html (cited 24 Sep 2013).

16. Tsukayama H. YouTube blocked in Pakistan. The Washington Post. 2012. http://www.washingtonpost.com/business/economy/youtubeblocked-in-pakistan/2012/09/17/30081fa2-00ea-11e2-b257e1c2b3548a4a_story.html (cited 24 Sep 2013). 
17. Fergana.news. Turkmenistan: YouTube and LiveJournal are blocked. $2009 \mathrm{http}: / /$ enews.fergananews.com/news. php?id=1516\&mode= snews (cited 24 Sep 2013).

18. Wainer J, Dabbish L, Kraut R. Should I open this email? In: Proceedings of the 2011 annual conference on human factors in computing systems - CHI' 11. New York, USA: ACM Press, 2011:3439-48. http://dl.acm.org/citation.cfm?doid=1978942. 1979456 (cited 7 Dec 2017).

19. Mood AM. On the asymptotic efficiency of certain nonparametric two-sample tests. Ann Math Stat 1954;25:514-22. 